\title{
Use of Facebook to Serve Information Needs of Persons with Diabetes in the Philippines amid the COVID-19 Pandemic
}

\author{
Iris Thiele Isip-Tan, ${ }^{1}$ Jerico Gutierrez, ${ }^{2}$ Diane Carla Bernardo ${ }^{3}$ \\ ${ }^{1}$ College of Medicine, University of the Philippines Manila \\ ${ }^{2}$ Community General Hospital of San Pablo City, Philippines \\ ${ }^{3}$ Davao Doctors Hospital, Philippines
}

\begin{abstract}
Objectives. The use of Facebook (FB) to share and gather information on diabetes is commonplace but no data is available on its use among Filipinos during the COVID-19 pandemic. We sought to determine the engagement from instructional slide decks on diabetes and its management shown on two Philippine-based FB pages under the Enhanced Community Quarantine (ECQ).

Methodology. We used Insights data from the slide decks and slide shows shown on the Philippine Society of Endocrinology, Diabetes and Metabolism's (PSEDM) public FB page and the Endocrine Witch's FB page. The slide set contained a mix of mostly images and text on COVID-19 and Diabetes, dietary advice, medications and self-care in the setting of the ECQ where access to insulin, ambulatory clinics and healthy food is limited. Data was summarized in terms of post clicks, reactions, shares and comments. Total engagement rate was computed.

Results. We noted a high engagement rate (4-15\%) in both public FB pages with higher engagement rates in slides shown in the Filipino language for most topics. The slides that gathered more shares and reactions were primarily those containing general information on COVID-19 and diabetes, nutrition including the safety of canned goods, as well as sick day rules.

Conclusion. In the setting of the ECQ, the use of image and text-based slide-decks on the PSEDM and Endocrine Witch FB pages to communicate health information yielded high engagement.
\end{abstract}

Key words: social media, health information, FB, diabetes mellitus, COVID-19

\section{INTRODUCTION}

Seventy-six million Filipinos are active social media users. FB is the most commonly utilized social media platform, used by $92 \%$ of all Filipinos with social media access from April 2019-April 2020. ${ }^{1}$

Even before the COVID-19 pandemic, Filipinos with diabetes have been using FB public support groups such as the Diabetes Health Community Support Group and the Philippine Diabetes Support Group having 8,339 and 16,564 members respectively (as of May 11, 2020). Smaller closed FB groups which are institution- or area-based like the Diabetes group of Koronadal (328 members), Knowledge and Care of Diabetes Center from Olongapo City (246 members), and Diabetes Education by Lucena Diabetes and Health Care Center (571 members), were also already formed. While a formal investigation has not been done on the topics shared by members within these Filipino groups, studies involving diabetes FB groups in other countries showed that posts on the latest diabetes research and providing education alongside sharing of personal experiences were the most common contents. ${ }^{2}$ De la Torre-Diez found 527 diabetes groups with a total of 564,023 users on FB and Twitter in 2011. The top three most common purposes of these diabetes groups were to find a cure for the disease, to support patients and their relatives and to provide information about diabetes. ${ }^{3}$

While FB can be a vast source of information including misinformation (Figure 1), it is still considered a popular and useful platform where questions from persons with diabetes and/or their relatives can be answered by public health institutions, healthcare professionals or other stakeholders. ${ }^{4}$ This is because the numbers of persons with diabetes continue to increase while physicians taking care of them may not always be available face-to-face because of locality or limited clinic hours among other reasons. The Philippines has a physician to patient ratio of 1:33,000 and only has 320 board-certified endocrinologists. These endocrinologists are also clustered in urban areas. Dr. Iris Thiele Isip-Tan, a Filipino endocrinologist, started her FB page Endocrine Witch in 2012. This page now has 153,507 followers (as of May 11, 2020); however, not more physicians are taking up her lead to go on social media to help combat online health misinformation.

Perhaps a better approach would be for organizations advocating for diabetes care to engage with Filipinos with diabetes online. In 2010, the Philippine Society 


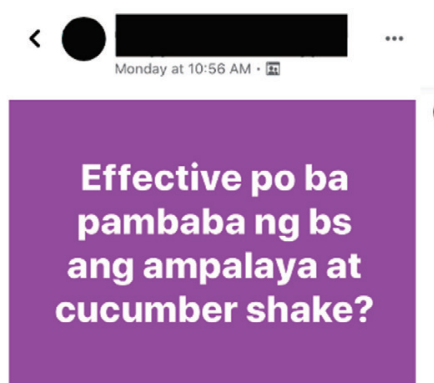

Diet Galore / Cheat Day Week or Month

ه Like $\square$ comment

(1) 33

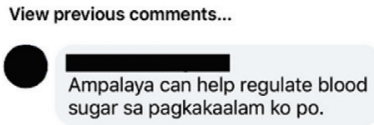
sugar sa pagkakaalam ko po.

A 3d Like Reply

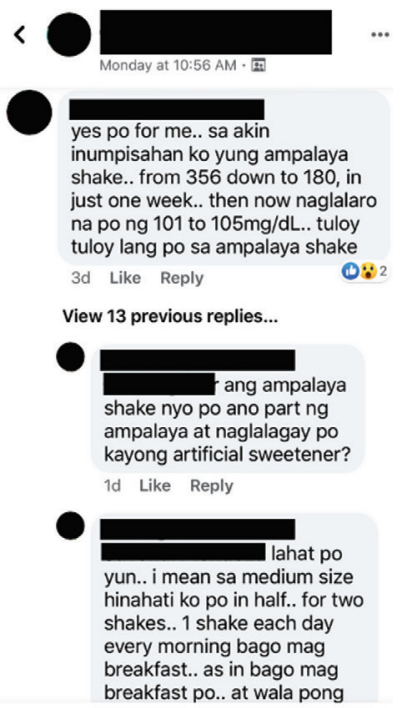

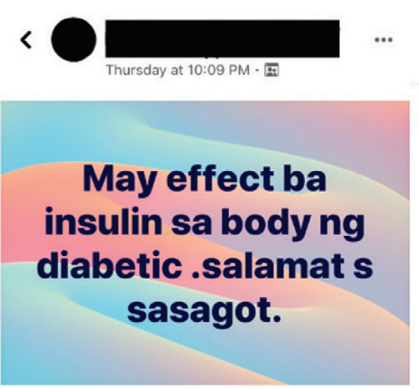

- Insulin / Patch / Sensor / Inhaler

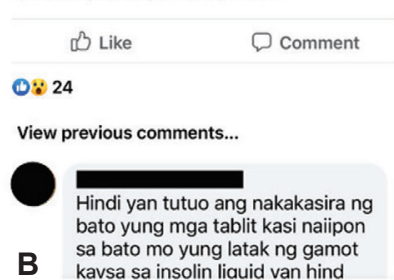

sa bato mo yung latak ng gamot

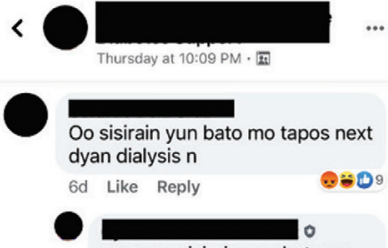

pano po sisirain ang bato $\mathrm{ng}$ insulin eh hindi naman dumadaan sa bato ang insulin? Direct na po siya and safer sa internal organs natin. 6d Like Reply $100_{8}$

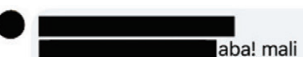
po yan kasweet mas mainam nga po ang insulin makakaiwas sa kidney failure compare sa sa kidney failure compare sa makakasira po talaga ng mi makakasira po talaga ng mga

6d Like Reply $00_{8}$

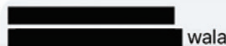

Figure 1. Misleading information about insulin and non-medicinal food to lower blood sugar. Translation: (A) Post: Are blended bitter gourd and cucumber effective for lowering blood sugar? First comment: Bitter gourd helps in regulating blood sugar as to my knowledge. Second comment: Yes. I started taking blended bitter gourd and my blood sugar went down from 365 to 180 in one week. (B) Post: Does insulin have an effect to the body. First comment: That's not true. Tablets are the ones that cause kidney damage because their residues accumulate in the kidney, unlike insulin which is liquid. Second comment: Yes. It will damage your kidney that will eventually lead to the need for dialysis. Third Comment: How can it damage your kidneys? It doesn't pass through the kidneys. It acts directly. Fourth comment: That is wrong it is better than tablets because you can avoid kidney failure. Tablets damage the kidneys.

of Endocrinology, Diabetes and Metabolism (PSEDM) established the Hormone Hotspots page as a way to share lay articles in the society's newsletter with 1,230 followers. It has maintained an FB page since January 16, 2020, and has 3,096 followers.

The first case of COVID-19 infection in the Philippines was confirmed on January 30, 2020. Subsequently, the Philippine government implemented enhanced community quarantine for the island of Luzon on March 16, 2020. This social distancing measure has affected continuity of care for people with diabetes as outpatient clinic services were temporarily suspended. Continuity of care and support for persons with diabetes is critical as they are more likely to get the severe form COVID-19 infection. Initial clinical data on COVID-19 studies show a high prevalence of diabetes among COVID-19 mortalities. ${ }^{5}$ It is crucial that blood glucose is maintained within treatment goals as this might help reduce the risk and severity of infection. ${ }^{6}$ As clinics are closed and health care needs for persons with diabetes continue, social media platforms like FB must be utilized to meet the need for guidance in self management of disease, such as dose adjustment on insulin, sick-day rules, proper diet, and to supply knowledge on how COVID-19 infection could affect persons with diabetes.

The COVID-19 pandemic is anticipated to have a sequelae of effects on public health. Tseng described these health footprints as the consequence and collateral damages brought about by the pandemic. As the healthcare system suffers from the direct effects of COVID-19 and resources are restricted on non-urgent clinical conditions, care for chronic illnesses like diabetes is negatively affected. This collateral damage of COVID-19 pandemic should be anticipated. Early preparation and employment of strategies to address the third wave effect of the pandemic is important. ${ }^{7}$ This paper explores how FB can be used to serve information needs of persons with diabetes amid the COVID-19 pandemic.

\section{METHODOLOGY}

During the community quarantine, frequent queries were posted at the Endocrine Witch FB group and at the Philippine Diabetes Support Group, regarding insulin substitution, lessening frequency of insulin injections and switching to generic brands for oral medications as Filipinos. At the same time, the Philippine Society of Endocrinology, Diabetes and Metabolism (PSEDM) through its Diabetes Advocacy Council realized the need to educate persons with diabetes about the relationship of COVID-19 infection and diabetes as the number of cases start to rise. The society initially posted a slide deck as photos in a FB album, in Filipino and in English language to educate persons with diabetes about COVID-19 infection and how it could potentially affect them. With the overwhelming number of queries and concerns raised about diabetes on FB, the author coordinated with the PSEDM Diabetes Advocacy council to address these concerns through more slide decks. Thirtysix members of PSEDM from all over the Philippines were recruited by the Diabetes Advocacy council and grouped into three teams. Each team was assigned topics related to diabetes care in the time of pandemic (Appendix A). Relevant topics were made based on the most common questions persons with diabetes posted on the Endocrine Witch and The Philippine Diabetes Support Group since March 16, 2020. On March 22, 2020, members of each group were assigned to be (1) content creators, (2) translators for two language formats [English and Filipino], and (3) graphics designers. The content of the slide decks were reviewed by a designated council to verify content before posting on social media (Figure 2). Coordination among 


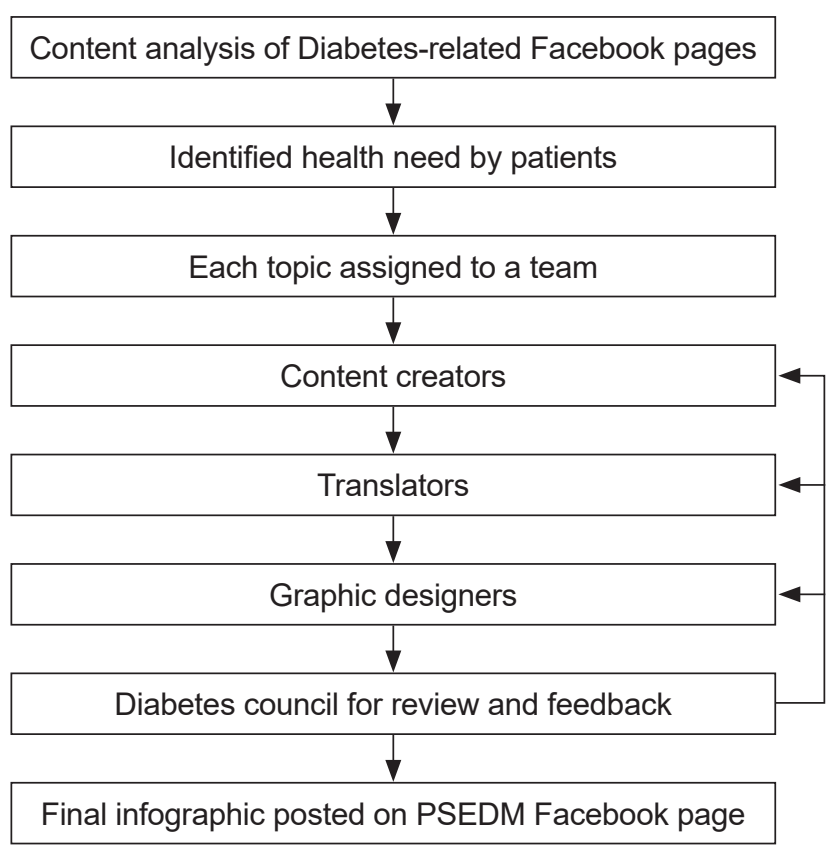

Figure 2. PSEDM workflow.

team members was through Viber and/or Slack. The slide decks were designed following a specific format such as font, font size, image size, and image and figure colors, in order to convey a uniform branding for PSEDM.

The slide deck format with photos measuring 1,600 x 630 pixels was used for this initiative. This is the standard size in FB that allows users to see the entire photo without having to click it. A series of photos was used instead of a long infographic, to deliver information in manageable chunks. The timing of posting varied between 9:00 AM and 11:00 PM. Except for one slide deck, the English and Filipino versions were posted on the same day.

On the other hand, Dr. Isip-Tan used the FB slideshow option to show the slide deck of photos for five seconds each in a video format on her FB page. Reminders to use the pause button were made to allow enough time for users to read and understand the content. As the slideshow option is limited only to ten photos, some of the slide deck sets were shown in two parts. Only the Filipino version of the topics were shared on her page. Although only 7 of the slide decks were shown as a slideshow, the engagement statistics from the page may still reveal insights regarding the video format and having more page followers and thus was included.

Figure 3 shows some of the examples posted on the official FB page of PSEDM (https://www.FB.com/ filipinoendocrinologists/). Each slide deck was posted on the official FB account of PSEDM as an album of photos. One topic, in both language formats, was posted every week. The process is shared here as an example of a medical society-led team approach in mounting a health information campaign on FB.

\section{RESULTS}

Appendix A shows statistics of engagement, available via the Insights panel of the FB page for the PSEDM and the Endocrine Witch FB pages respectively. These statistics were gathered on May 16, 2020, 23 days after the last slide deck was posted. Though older posts may have possibly accumulated more engagement, this may not unduly affect the results. Bhattacharya et al., in a social media engagement analysis of US Federal health agencies on FB found that $80 \%$ of a post's last activity was on the day of posting. ${ }^{8}$

In the hierarchy of engagement with FB posts, reactions (thumbs up, heart, sad face etc.) are considered the lowest form of engagement since it employs a simple and quick response. Sharing, on the other hand, is considered a medium form of engagement since the user is able to identify with the post's content, prompting the user to share it in his or her own FB account. Commenting is considered as the highest form of engagement because this action involves a process wherein a user reflects on a topic, formulates a text, and states it publicly on FB. ${ }^{9}$

Noticeably the more common forms of engagements in all of the PSEDM's slide decks (regardless of language used) and the Endocrine Witch's slideshows are reactions and shares. There were only 120 comments in all the slide decks, both in English and Filipino formats in the PSEDM FB page. These included tagging other FB users to read the infographic, thanking the person who shared the post, and lastly other comments such as (consult 1 , sharing personal problem 1, direct message to the person who shared the post 1). While there were more comments on the Endocrine Witch slideshows, the themes of the comments were similar.

For both English and Filipino versions of PSEDM's slide deck, the themes with the highest engagement rates were those giving general information on diabetes and its management: types, proper use of and storage of insulin (English), and diabetes and COVID-19 (Filipino). Themes about diabetes self-management such as general sick day rules (English) or medication-adjustment in the event of diarrhea (Filipino) followed, with engagement rates as high as 9 and 13 percent respectively. Diabetes selfmanagement slides on hyperglycemia and hypoglycemia (English) were the next most visited, while this did not hold true for its Filipino counterpart. Instead, more users clicked on the slide decks on the safety of canned goods for persons with diabetes as well as the proper diabetic diet during the pandemic. We also observed that across all topics, there was a greater engagement rate in the slide decks presented in Filipino (7 out of 12).

A similar pattern in themes is observed from the Endocrine Witch's page with the highest engagement rates coming from topics about diabetes and COVID-19, diarrhea and oral medication adjustment, brand switching in case stocks of medications run out, as well as hypoglycemia selfmanagement. No stats are available for diet management as the slide deck on the topic was not included in the page.

\section{DISCUSSION}

The interruption of regular ambulatory clinics because of the COVID-19 pandemic has presented a challenge in the care continuum of persons with diabetes. This study showed that the use of FB as a platform to educate about COVID-19 and to provide helpful instruction on 

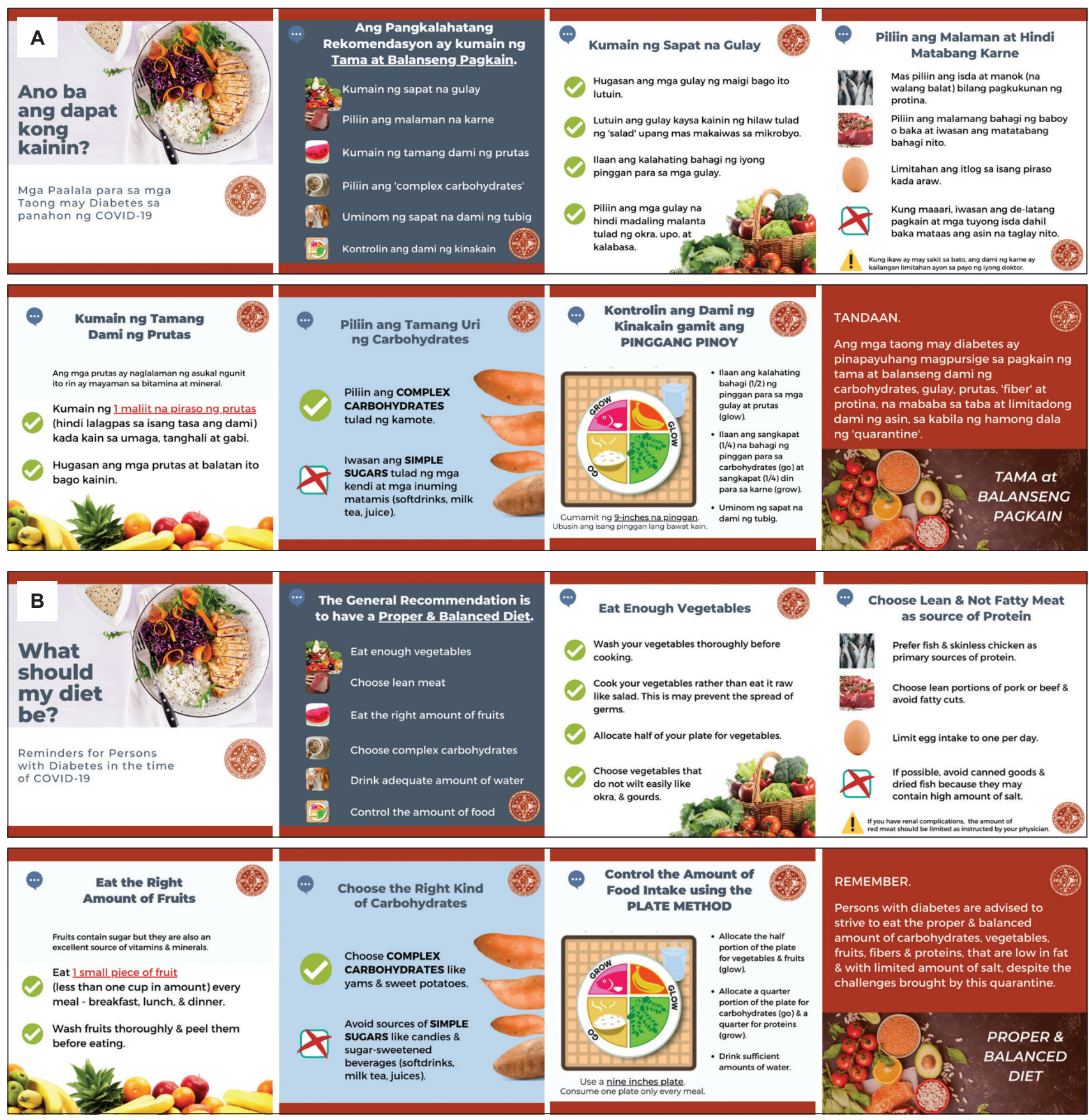

Figure 3. Examples of infographics posted on the Philippine Society of Endocrinology, Diabetes, and Metabolism FB page (A) in Filipino and (B) in English. (Adapted from https://www.facebook.com/filipinoendocrinologists).

diabetes self-management is doable and yields high user engagement.

The predominant themes on diabetes management, and diet seen in this project mirror findings of studies done even pre-pandemic where social media users would visit more posts on management, diabetes technology and nutrition than any other diabetes-related topic ${ }^{9,10}$ or were more likely to engage in posts on FB groups/communities about different diabetes management strategies shared by patients. ${ }^{11}$ Although no paper on FB use and diabetes care during the era of COVID-19 has been published so far to our knowledge, the high engagement rate seen particularly for PSEDM's slide decks on diabetes self-management (i.e., insulin uptitration, diarrhea and sick-day management, adjustment of insulin during exercise) may be a reflection of the current interest and/or information needs of Filipino social media users whether for themselves or for their relatives and friends during this pandemic. Social media users tend to patronize posts that are relevant to them. It may be to reinforce what was already taught to them by their physician, or may actually be the very first medium of instruction for them on a topic, which was not tackled during prior clinic visits.

PSEDM's Diabetes Advocacy council made use of photos/ infographics to convey information towards its potential consumers. In general, health information can be uploaded on FB in many different formats i.e., text only, images, videos, or links. There are conflicting results as to which 
format is more effective and engaging in providing health information. In a participative study done on the social media followers of the Norwegian Diabetes Association, the preferred format of health information varied according to age. Text format was preferred by adults and images were preferred by younger individuals. ${ }^{4}$ However, another study showed that images in the post were the strongest predictor of likes, shares, or comments. Images have been described to be effective in modifying behavior through communication responses. Information relayed via images are processed faster, retained, and retrieved from memory by eliciting strong emotional reactions. ${ }^{12}$ Information in graphic format is also believed to enhance understanding and ability to make decisions. ${ }^{13}$

Meanwhile, another study showed that videos attracted the greatest amount of user engagement as opposed to links and text-only formats even if the topic is of great relevance. ${ }^{14}$ We surmise that the use of photos and slide-shows (videos) in the PSEDM and the Endocrine Witch's page not only provided a medium that was easily understandable but was something that was also preferred by most Filipino FB users and thus helped in achieving the high engagement. Perhaps a survey or focused group discussion on patient preferences must be done to identify the most effective format for communicating health information and one that will maximize user engagement.

An average engagement rate on a FB post is $3.22 \% .^{15}$ All posts in the PSEDM and the Endocrine Witch FB accounts had an above average engagement rate. We also noted a higher engagement rate in the slide decks presented in the Filipino language versus English. Intuitively, persons with diabetes or persons taking care of them would likely choose a language which they can easily comprehend in order to maximize the learning from a post and likewise communicate it effectively to others. Still, there may be other elements accounting for the high engagement seen.

Evidence-based guidelines in commissioning health infographics for use with the public health suggest the following principles of design: familiarization with the audience and the key message that must be shared, restriction of the number of colors used in the design, alignment of elements of the design consistently, prioritization of parts focal points in the infographic, emphasis on heading, wise use of imagery, careful selection and use of charts or graphs. ${ }^{16}$ A study done by McKown that developed an infographic and made a formative assessment on it by conducting a survey on diabetes educators showed that the health educators believe that infographics are accurate, easy to understand for diabetes educators, and agreed that these infographics would be understable by consumers as well. Open ended questions in the survey revealed recommendations such as utilizing colors for infographics to make it visually appealing, adding contact information for further information, utilizing a bigger font size, and using gender neutral images. ${ }^{17}$

Another study on young individuals tried to evaluate key characteristics of nutrition infographics that will make them more memorable and compelling revealed that actionoriented titles were related to better message recall than the use of color or humor. This result suggests that a carefully created title is an important key element to the effectiveness of infographics together with short texts all throughout the infographic. ${ }^{18}$ These findings emphasize important features of infographics that will make them effective and should be considered in designing infographics for public health consumption.

As this was a society-led initiative, the slide decks used a uniform font, font size, image size, and image and figure colors. This is worth noting as a study by Park et al., of health organizations' FB pages showed that most organizations were not using branding techniques. Branding may be crucial in that the public may easily recognize and trust the information being presented more if it is known to be by a reputable medical society. ${ }^{19}$

Another social media platform that is used to share pictures is Pinterest. Users can interact with a post called a pin, by liking, commenting, or saving a pin to a user's collection of photos. A study performed a content analysis of 238 diet-related infographics and pictures that promote healthy eating posted on Pinterest. Results revealed that most infographics did not contain health behavior theory constructs but those that contained them had a higher user interaction in the form of repins, likes and comments. Characteristics of infographics that contain health behavior theory constructs include use of text, a photograph of a real person or a cartoon, or images of food. However, less than half of infographics included in the analysis had images of real people. The study suggested that using more realistic images in infographics may be more likely to promote behavioral change like promoting good eating habits. ${ }^{20}$ Another content analysis study on 214 images and infographics posted on Pinterest for COPD self-management revealed the use of photographs of real people was associated with higher user engagement. Photographs of real people presenting with COPD selfmanagement information had more likes and infographics were repinned or saved more. The results of these studies can serve as a guideline in making an effective image for social media use and should be considered in every infographic or image design. ${ }^{21}$

Lastly, we noted a low number of comments in both pages as opposed to reactions and shares. This finding is similar with the results of a study done by Rus and Cameron. They theorized that the images either fail to stimulate comments or potentially inhibit commenting from users. This relationship remains to be elucidated but there is a possibility that images stimulate concrete-experiential processing of messages, which stimulates reactions such as liking and sharing but inhibits the abstract, linguistic processes employed in writing comments. ${ }^{22-23}$

\section{Limitations}

The images made by PSEDM and the slideshow posted on the Endocrine Witch FB page were based on the most common concerns posted on popular diabetes support FB pages based in the Philippines. However, the parameter with which success of disseminating information could be measured was not predefined. Being a project that was not originally intended for research but for advocacy purposes only, no such definitions of success in spreading health information with the use of infographics were made other than the counts of engagements. Given the potential of the use of images and infographics in disseminating 
information, it is crucial to establish the evidence on its efficacy in relaying information and determine the characteristics or elements of an infographic that make them more effective.

\section{CONCLUSION/RECOMMENDATION}

The power of social media together with the effectiveness of images in conveying information should be harnessed to promote public health. Patient health information needs must be identified and key characteristics of an effective image or infographic must be used wisely in order to stimulate the reader's attention, relay information effectively, and enhance retention and hopefully, effect a call to action.

\section{Statement of Authorship}

The authors certified fulfillment of ICMJE authorship criteria.

\section{Author Disclosure}

The authors declared no conflict of interest. All authors are active members of the Philippine Society of Endocrinology, Diabetes and Metabolism (PSEDM).

\section{Funding Source}

None.

\section{References}

1. Social Media Stats Philippines. gs.statcounter.com. Accessed May 16, 2020.

2. AlQarni ZA, Yunus F, Househ MS. Health information sharing on Facebook: An exploratory study on diabetes mellitus. J Infect Public Health. 2016;9(6):708-12. PMID: 27618634. https://doi.org/10.1016/j. jiph.2016.08.015.

3. De la Torre-Diez I, Díaz-Pernas FJ, Antón-Rodríguez M. A content analysis of chronic diseases social groups on Facebook and Twitter. Telemed J E Health. 2012;18(6):404-8. PMID: 22650380. https://doi. org/10.1089/tmj.2011.0227.

4. Gabarron E, Dorronzoro E, Bradway M, Rivera-Romero O, Wynn R, Årsand E. Preferences and interests of diabetes social media users regarding a health-promotion intervention. Patient Prefer Adherence. 2018;12:2499-506. PMID: 30538433. PMCID: PMC6260177. https://doi. org/10.2147/PPA.S184369.

5. Onder G, Rezza G, Brusaferro S.Case-Fatality rate and characteristics of patients dying in relation to COVID-19 in Italy. JAMA. 2020. PMID: 32203977. https://doi.org/10.1001/jama.2020.4683.

6. Gupta R, Ghosh A, Singh A, Misra A. Clinical considerations for patients with diabetes in times of COVID-19 epidemic. Diabetes Metab Syndr. 2020;14(3):211-12. PMID: 32172175. PMCID: PMC7102582. https://doi.org/10.1016/j.dsx.2020.03.002.

7. Tseng V. Available at https://www.twitter.com/VectorSting/status/124 4671755781898241?s=19" https://www.twitter.com/VectorSting/status/ 1244671755781898241?s=19. Accessed May 6, 2020.

8. Bhattacharya S, Srinivasan P, Polgreen P. Social media engagement analysis of U.S. Federal health agencies on Facebook. BMC Med Inform Decis Mak. 2017;17(1):49. PMID: 28431582. PMCID: PMC5401385. https://doi.org/10.1186/s12911-017-0447-z.
9. Biancovilli B, Jurberg C. How to optimize health messages about cancer on Facebook: Mixed-methods study. JMIR Cancer. 2018;4(2):e11073. PMID: 30563821. PMCID: PMC6315252. https://doi.org/10.2196/11073.

10. Shaffer-Hudkins E, Johnson N, Melton S, Wingert A. Social media use among individuals with diabetes. Int J Comm Health. 2014;4:38-43. http://communicationandhealth.ro/upload/number4/SHAFFERHUDKINS-JOHNSON-MELTON-WINGLERT.pdf.

11. Greene J, Choudhry N, Kilabuk E, Shrank W. Online social networking by patients with diabetes: A qualitative evaluation of communication with Facebook. J Gen Intern Med. 2011;26(3):287-92. PMID: 20945113 PMCID: PMC3043192. https://doi.org/10.1007/s11606-010-1526-3.

12. Rus HM, Cameron LD. Health communication in social media: Message features predicting user engagement on diabetes-related Facebook pages. Ann Behav Med. 2016;50(5):678-89. PMID: 27059761 https://doi.org/10.1007/s12160-016-9793-9.

13. Spiegelhalter D, Pearson M, Short I. Visualizing uncertainty about the future. Science. 2011;333(6048):1393-400. PMID: 21903802. https://doi. org/10.1126/science.1191181.

14. Kite J, Foley BC, Grunseit AC, Freeman B. Please like me: Facebook and public health communication. PLoS ONE. 2016;11(9):e0162765. PMID: 27632172. PMCID: PMC5025158. https://doi.org/10.1371/ journal pone. 0162765 .

15. Rabo O. Average Facebook engagement rate. https://blog.iconosquare. com/average-facebook-engagement-rate/. Accessed May 16, 2020.

16. Stones C, Gent Mike. The 7 G.R.A.P.H.I.C. principles of graphic health infographic design. Leeds. University of Leeds, Public Health England, 2015. https://improvementacademy.org/documents/Projects/ air_quality/The $\% 207 \% 20$ Graphic $\% 20$ Principals $\% 20$ of $\% 20$ Public $\% 20$ Health\%20Infographic\%20Design.pdf.

17. McKown H. Development and formative assessment of a type 2 diabetes social marketing infographic. Oklahoma State University, United States of America, 2016. Retrieved from https://shareok.org/ bitstream/handle/11244/49115/McKown_okstate_0664M_14470. pdf? sequence $=1 \&$ is Allowed $=y$

18. Wansink B, Robbins R. Which design components of nutrition infographics make them memorable and compelling? Am J Health Behav. 2016;40(6):779-87. PMID: 27779946. https://doi.org/10.5993/ AJHB.40.6.10.

19. Park $\mathrm{H}$, Rodgers $\mathrm{S}$, and Stemmle J. Health Organizations' use of Facebook for health advertising and promotion, J Interact Advert. 2011;12(1):62-77. https://doi.org/10.1080/15252019.2011.10722191.

20. Wilkinson JL, Strickling K, Payne HE, Jensen KC, West JH. Evaluation of diet-related infographics on Pinterest for use of behavior change theories: A content analysis. JMIR Mhealth Uhealth. 2016;4(4): e133. PMID: 27932316. PMCID: PMC5179977. https://doi.org/mhealth.6367.

21. Paige SR, Stellefson M, Chaney BH, Alber JM. Pinterest as a resource for health information on chronic obstructive pulmonary disease (COPD): A social media content analysis. Am J Health Educ. 2015;46(4):241-51. https://doi.org/10.1080/19325037.2015.1044586.

22. Leventhal H, Leventhal E, Cameron LD. Representations, procedures, and affect in illness self regulation: A perceptual-cognitive approach. In: Baum A, Revenson T, Singer J, eds. Handbook of Health Psychology. New York: Erlbaum; 2001.

23. Epstein S, Pacini R. The influence of visualization on intuitive and analytical information processing. Imagination, Cognition and Personality. 2001;20(3):195-216. https://doi.org/10.2190/G4VG-AKQP2Q91-JQHP.

Authors are required to accomplish, sign and submit scanned copies of the JAFES Author Form consisting of: (1) Authorship Certification, that authors contributed substantially to the work, that the manuscript has been read and approved by all authors, and that the requirements for authorship have been met by each author; (2) the Author Declaration, that the article represents original material that is not being considered for publication or has not been published or accepted for publication elsewhere, that the article does not infringe or violate any copyrights or intellectual property rights, and that no references have been made to predatory/ suspected predatory journals; (3) the Author Contribution Disclosure, which lists the specific contributions of authors; and (4) the Author Publishing Agreement which retains author copyright, grants publishing and distribution rights to JAFES, and allows JAFES to apply and enforce an Attribution-Non-Commercial Creative Commons user license. Authors are also required to accomplish, sign, and submit the signed ICMJE form for Disclosure of Potential Conflicts of Interest. For original articles, authors are required to submit a scanned copy of the Ethics Review Approval of their research as well as registration in trial registries as appropriate. For manuscripts reporting data from studies involving animals, authors are required to submit a scanned copy of the Institutional Animal Care and Use Committee approval. For Case Reports or Series, and Images in Endocrinology, consent forms, are required for the publication of information about patients; otherwise, appropriate ethical clearance has been obtained from the institutional review board. Articles and any other material published in the JAFES represent the work of the author(s) and should not be construed to reflect the opinions of the Editors or the Publisher. 


\section{Appendix A.}

Table 1. FB-derived engagement statistics for photo albums on PSEDM FB page

\begin{tabular}{|c|c|c|c|c|c|c|c|}
\hline Title & Language/Date/Time posted & Post clicks & Reaction* & Comments & Shares & Reach & $\begin{array}{c}\text { Engagement } \\
\text { Rate }(\%)^{\star *}\end{array}$ \\
\hline \multirow{2}{*}{$\begin{array}{l}\text { Diabetes in the Time of COVID-19 } \\
\text { (Risks, mortality, general information) }\end{array}$} & English 03/24/2020 1:05 PM & 3 & 0 & 0 & 1 & 76 & 4 \\
\hline & Filipino 03/21/2020 11:51 AM & 9,562 & 1,291 & 29 & 446 & 57,271 & 15 \\
\hline \multirow{2}{*}{$\begin{array}{l}\text { What are The Types of Insulin? } \\
\text { (Background knowledge on different kinds } \\
\text { of insulin, duration of action, onset, etc) }\end{array}$} & English 03/29/2020 10:58 PM & 146 & 14 & 0 & 1 & 948 & 12 \\
\hline & Filipino 03/29/2020 11:07 PM & 59 & 27 & 1 & 6 & 1,273 & 5 \\
\hline \multirow{2}{*}{$\begin{array}{l}\text { Oral Medications of Persons with } \\
\text { Diabetes (Information about oral } \\
\text { medications and brand substitution) }\end{array}$} & English 04/07/2020 9:41 AM & 111 & 34 & 0 & 11 & 1,905 & 6 \\
\hline & Filipino 04/07/2020 9:48 AM & 69 & 22 & 4 & 1 & 744 & 11 \\
\hline \multirow{2}{*}{$\begin{array}{l}\text { Diarrhea in COVID-19 } \\
\text { (Diarrhea and medication adjustment) }\end{array}$} & English 03/27/2020 9:32 PM & 37 & 41 & 2 & 9 & 841 & 7 \\
\hline & Filipino 03/27/2020 9:36 PM & 5,643 & 717 & 39 & 307 & 42,172 & 13 \\
\hline \multirow{2}{*}{$\begin{array}{l}\text { How to monitor your blood sugar? } \\
\text { (Knowledge on blood sugar monitoring) }\end{array}$} & English 04/01/2020 10:32 PM & 118 & 46 & 0 & 17 & 2,130 & 6 \\
\hline & Filipino 04/01/2020 10:45 PM & 83 & 39 & 0 & 16 & 1,305 & 8 \\
\hline \multirow{2}{*}{$\begin{array}{l}\text { Hyperglygemia or High Blood } \\
\text { Sugar-What to Do? (Hyperglycemia } \\
\text { and insulin adjustment) }\end{array}$} & English 04/03/2020 9:41 PM & 108 & 36 & 2 & 8 & 1,071 & 8 \\
\hline & Filipino 04/03/2020 9:45 PM & 55 & 36 & 1 & 5 & 1,148 & 6 \\
\hline \multirow{2}{*}{$\begin{array}{l}\text { Hypoglycemia or Low Blood Sugar- } \\
\text { What to Do? Hypoglycemia, symptoms, } \\
\text { first aid treatment, and insulin adjustment }\end{array}$} & English 04/04/2020 8:18 PM & 151 & 37 & 7 & 57 & 917 & 8 \\
\hline & Filipino 04/04/2020 8:21 PM & 77 & 57 & 1 & 5 & 1,552 & 9 \\
\hline \multirow{2}{*}{$\begin{array}{l}\text { Diabetes During an Illness } \\
\text { (Sick-day rules) }\end{array}$} & English 04/19/2020 11:53 AM & 234 & 17 & 3 & 16 & 2,335 & 9 \\
\hline & Filipino 04/19/2020 11:57 AM & 107 & 6 & 11 & 13 & 2,855 & 4 \\
\hline \multirow{2}{*}{$\begin{array}{l}\text { Matching Insulin with Food Intake } \\
\text { (Insulin matching with food) }\end{array}$} & English 04/15/2020 8:59 PM & 127 & 1 & 0 & 5 & 1,064 & 9 \\
\hline & Filipino 04/19/2020 11:57 AM & 107 & 17 & 3 & 16 & 1,450 & 7 \\
\hline \multirow{2}{*}{$\begin{array}{l}\text { Adjusting Insulin Dose for Exercise } \\
\text { (Exercise and precautions for } \\
\text { persons using insulin) }\end{array}$} & English 04/23/2020 11:02 AM & 134 & 2 & 1 & 5 & 1,364 & 8 \\
\hline & Filipino 04/23/2020 11:05 AM & 161 & 48 & 2 & 29 & 2,036 & 8 \\
\hline \multirow{2}{*}{$\begin{array}{l}\text { Is It Safe to Eat Canned Goods? } \\
\text { (Safety of canned goods due to } \\
\text { limited access to quality food) }\end{array}$} & English 04/08/2020 10:16 PM & 71 & 45 & 1 & 6 & 2,088 & 8 \\
\hline & Filipino 04/08/2020 10:20 PM & 200 & 141 & 18 & 25 & 910 & 12 \\
\hline \multirow{2}{*}{$\begin{array}{l}\text { What Should My Diet Be? } \\
\text { (Proper diet during a pandemic) }\end{array}$} & English 04/09/2020 11:09 PM & 89 & 19 & 0 & 8 & 1,499 & 6 \\
\hline & Filipino 04/09/2020 11:12 PM & 148 & 200 & 6 & 35 & 2,566 & 9 \\
\hline
\end{tabular}

Table 2. FB-derived engagement statistics for slideshows on Endocrine Witch FB page (Adapted from https://www. facebook.com/EndocrineWitch)

\begin{tabular}{|c|c|c|c|c|c|c|c|}
\hline Title * & Date/Time posted & Post clicks & Reactions & Comments & Shares & Reach & $\begin{array}{c}\text { Engagement } \\
\text { Rate }(\%)\end{array}$ \\
\hline Diabetes in the Time of COVID-19 & 03/21/2020 11:19 AM & $6,100^{* *}$ & 981 & 188 & 738 & 59,133 & 10 \\
\hline What are The Types of Insulin? & 03/30/2020 8:00 AM & $1,100^{* *}$ & 292 & 25 & 125 & 16,352 & 6 \\
\hline Diarrhea in COVID-19 & 03/31/2020 9:25 AM & $2,700^{* *}$ & 472 & 44 & 251 & 25,307 & 10 \\
\hline How to monitor your blood sugar? & 04/02/2020 8:05 PM & 868 & 223 & 33 & 95 & 14,361 & 6 \\
\hline Part 1. Insulin Adjustment & 04/04/2020 9:47 AM & 749 & 194 & 18 & 85 & 14,582 & 5 \\
\hline $\begin{array}{l}\text { Part 2. Insulin Adjustment [premixed or } \\
\text { combination insulin] }\end{array}$ & 04/04/2020 10:09 AM & 429 & 147 & 9 & 48 & 10,639 & 5 \\
\hline $\begin{array}{l}\text { Part 1. Oral Medications of Persons } \\
\text { with Diabetes }\end{array}$ & 04/07/2020 12:44 PM & 689 & 205 & 4 & 43 & 10,639 & 7 \\
\hline $\begin{array}{l}\text { Part 2. Oral Medications of Persons } \\
\text { with Diabetes }\end{array}$ & 04/07/2020 12:50 PM & $1,800^{* *}$ & 370 & 26 & 176 & 20,550 & 8 \\
\hline $\begin{array}{l}\text { Part } 1 \text { Hypoglycemia or Low Blood Sugar- } \\
\text { What to Do? }\end{array}$ & 04/08/2020 6:30 PM & 578 & 114 & 9 & 50 & 7,306 & 7 \\
\hline Part 2. Insulin Adjustment for Hypoglycemia & 04/08/2020 6:40 PM & 649 & 157 & 27 & 57 & 13,635 & 5 \\
\hline
\end{tabular}

